J.Lake Sci.(湖泊科学) , 2016, 28(1): 75-85

DOI 10. 18307/2016. 0109

(c) 2016 by Journal of Lake Sciences

\title{
滇池表层沉积物铵态氮吸附特征
}

\author{
邓伟明, 徐晓梅, 陈春瑜, 何 佳 ${ }^{* *}$, 许 迪, 王 丽 \\ (昆明市环境科学研究院湖泊水库中心, 昆明 650032)
}

\begin{abstract}
摘 要: 为研究滇池内源污染特征, 2013 年利用 GIS 软件针对滇池全湖布设 36 个采样点, 采集表层沉积物, 研究滇池表 层沉积物铵态氮 $\left(\mathrm{NH}_{4}^{+}-\mathrm{N}\right)$ 吸附特征, 同时分析沉积物的理化性质对 $\mathrm{NH}_{4}^{+}-\mathrm{N}$ 吸附特性的影响. 结果表明: 滇池表层沉积物 对 $\mathrm{NH}_{4}^{+}-\mathrm{N}$ 的吸附量在前 $2 \mathrm{~h}$ 之内呈增长趋势, 吸附速率较大, 之后沉积物对 $\mathrm{NH}_{4}^{+}-\mathrm{N}$ 的吸附量不随时间变化而变化, 基本 达到平衡, 最大吸附速率均发生在 $0 \sim 5 \mathrm{~min}$ 内; 不同区域表层沉积物 $\mathrm{NH}_{4}^{+}-\mathrm{N}$ 最大吸附速率平均值表现为: 外海南部>湖心 区>外海北部 $>$ 草海, 最大吸附量平均值表现为: 湖心区>外海南部>外海北部>草海, 吸附效率平均值表现为: 外海北部> 草海>湖心区>外海南部; 沉积物对 $\mathrm{NH}_{4}^{+}-\mathrm{N}$ 的吸附量与 $\mathrm{NH}_{4}^{+}-\mathrm{N}$ 的初始浓度大致呈线性关系, 并且低浓度下表现出很好的 吸附/解吸特征; 滇池表层沉积物 $\mathrm{NH}_{4}^{+}-\mathrm{N}$ 的吸附解吸平衡浓度 $\left(E N C_{0}\right)$ 高于上覆水中 $\mathrm{NH}_{4}^{+}-\mathrm{N}$ 浓度, 表明沉积物中 $\mathrm{NH}_{4}^{+} \mathrm{N}$ 有向上覆水中释放的风险, 沉积物在很长一段时间内起到水体污染 “源” 的作用; $E N C_{0}$ 与沉积物中总氮、 $\mathrm{NH}_{4}^{+}-\mathrm{N}$ 含量呈显 著正相关, 本底吸附量和有机质总量呈显著负相关, 沉积物吸附 $\mathrm{NH}_{4}^{+}-\mathrm{N}$ 主要受有机质的影响.
\end{abstract}

关键词: 滇池; 沉积物; 铵态氮; 吸附

\section{Sorption and desorption characteristics of ammonium in the surface sediments of Lake Di- anchi}

DENG Weiming, XU Xiaomei, CHEN Chunyu, HE Jia**, XU Di \& WANG Li

(Research Center of Lakes and Reservoirs, Kunming Institute of Environmental Sciences, Kunming 650032, P.R.China)

Abstract: In order to study the endogenous pollution characteristics of Lake Dianchi, 36 samples were set in whole Lake Dianchi using the GIS exploring in 2013. Through collecting the surface sediment samples, adsorption characteristics of ammonia on surface sediments were studied and the influence of physical and chemical properties of sediments on the adsorption characteristics of ammonia was also analyzed. The results showed that the adsorption quantity of ammonia nitrogen on surface sediments of the Lake Dianchi showed a growing trend in $2 \mathrm{~h}$ and the adsorption rate was relatively high. After $2 \mathrm{~h}$, the adsorption quantity of ammonia on surface sediments did not change with time and attain the basic balance. The maximum adsorption rate appeared during $0-5$ min. An order of the average maximum adsorption rate of ammonia on sediments of different sub-lake waters was: the south of Lake Waihai>the center of the lake>the south of Lake Waihai>Lake Caohai. An order of the average of maximum adsorbent quantity was: the center of the lake>the south of Lake Waihai>the north of Lake Waihai>Lake Caohai. A order of the average adsorption efficiency was: the north of Lake Waihai>Lake Caohai>the center of the lake>the south of Lake Waihai. The adsorption quantity of ammonia on sediments showed a rough linear relationship with the initial concentration of ammonia. Under a low concentration condition, a good adsorption/desorption characteristic occurred. Through comparing the concentration of adsorption/desorption of ammonia on sediments and the concentration between overlying water and sediments, the results showed that the $E N C_{0}$ of ammonia in sediments was higher than that in overlying water, indicating that the ammonia had the releasing risk from sediments to overlying water. These inferred that the sediments would play a role of the water pollution "source" in a long time. As $E N C_{0}$ had the positive correlation with total nitrogen and ammonium nitrogen in sediments and $N A N$ had negative correlation with total organic matter, we recognized that the ammonia adsorbed by sediments was mainly influenced by organic matter.

* 国家水体污染控制与治理科技重大专项(2012ZX07102) 资助.2014-12-17 收稿; 2015-07-02 收修改稿. 邓伟明 (1984 ), 男,硕士,助理工程师;E-mail: ming_605@163.com.

** 通信作者;E-mail:dcszxb@163.com. 
Keywords: Lake Dianchi; sediments; ammonia nitrogen; adsorption

在水环境氮素的循环中,沉积物-水界面硝态氮 $\left(\mathrm{NO}_{3}^{-}-\mathrm{N}\right)$ 和铵态氮 $\left(\mathrm{NH}_{4}^{+}-\mathrm{N}\right)$ 的扩散通量起非常重要的 作用 ${ }^{[1-2]}$, 在溶解氧充足的条件下, 沉积物中的有机氮化物经矿化作用, 生成 $\mathrm{NH}_{4}^{+}$和 $\mathrm{NO}_{3}^{-}$等离子扩散进人上 覆水体中, 增加水体氮浓度; 同时水体中 $\mathrm{NH}_{4}^{+}$和 $\mathrm{NO}_{3}^{-}$等无机离子也会逆向扩散至沉积物中, 吸附在沉积物颗 粒物上. 即表层沉积物对氮素的吸附和解吸过程是双向可逆过程, 并且在整个循环交换过程中氮素主要以 $\mathrm{NH}_{4}^{+}-\mathrm{N}$ 形式存在 ${ }^{[3-4]}$.

滇池是我国西南地区面积最大的内陆浅水湖泊, 被列为 13 个重点保护水系之一 ${ }^{[5]}$, 随着经济快速发 展, 滇池水环境污染日趋严重, 其中草海异常富营养化, 局部沼泽化, 外海严重富营养化 ${ }^{[6]}$, 导致滇池污染加 重的原因除了与外源氮、磷等营养元素的大量排人有关外, 底泥中沉积的营养元素也起到非常关键的作用, 特别是在外源污染得到有效控制后, 内源污染的潜在危害开始逐渐显现, 因此, 研究滇池表层沉积物对 $\mathrm{NH}_{4}^{+}-\mathrm{N}$ 的吸附/解吸特征对了解沉积物一水界面氮素的交换过程, 明确滇池富营养化的进程是十分必要的.

\section{1 材料与方法}

\section{1 研究区概况}

滇池 $\left(24^{\circ} 28^{\prime} \sim 25^{\circ} 28^{\prime} \mathrm{N}, 102^{\circ} 30^{\prime} \sim 103^{\circ} 0^{\prime} \mathrm{E}\right)$ 位于昆明市南的西山脚下, 是我国第 6 大淡水湖泊 ${ }^{[7]}$, 呈南北向 分布, 东北部有一长 $4 \mathrm{~km}$ 的天然沙堤, 将滇池分为南北两部分, 分别称为外海和草海; 草海面积 $7.52 \mathrm{~km}^{2}$, 湖容

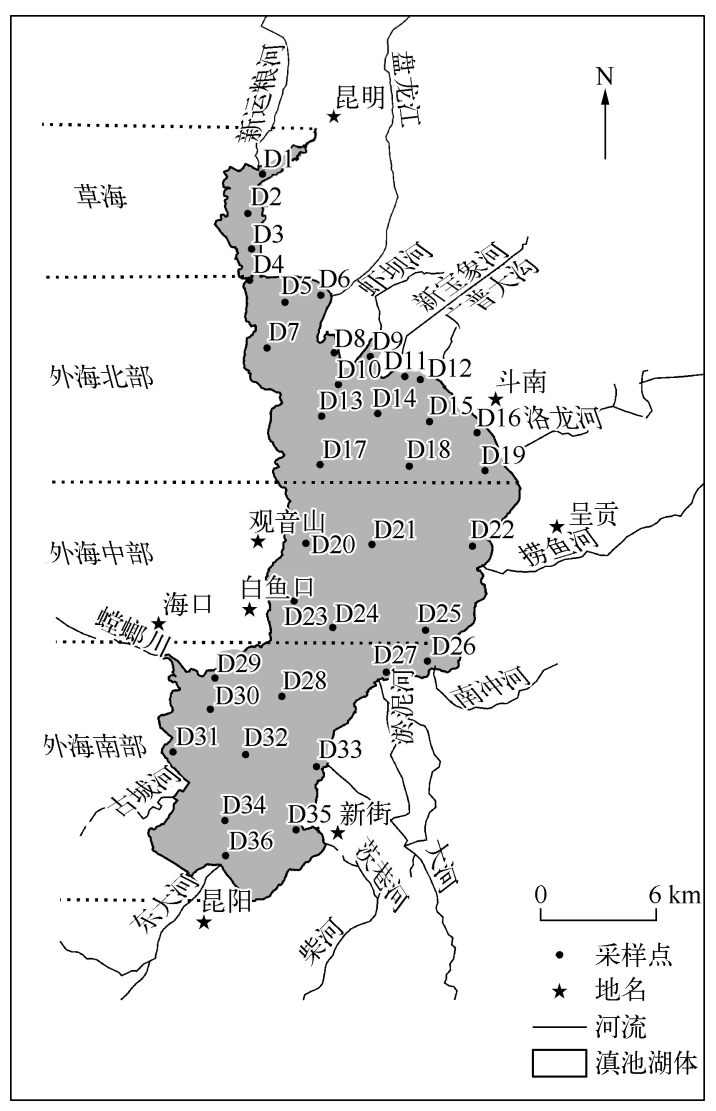

图 1 滇池沉积物与水样监测点位

Fig.1 Sediment and water monitoring sites of Lake Dianchi $0.188 \times 10^{8} \mathrm{~m}^{3}$, 外海面积为 $287.10 \mathrm{~km}^{2}$, 湖容约 $13.60 \times 10^{8} \mathrm{~m}^{3}$, 最大水深 $10.24 \mathrm{~m}$, 平均水深 $4.40 \mathrm{~m}^{[8]}$.

\section{2 研究点位及采样方法}

2013 年在滇池全湖布设 36 个点位, 包含常 规监测点位、人滇河流人湖口监测点位和疏浚区 监测点位, 然后利用 GPS 定位进行采样, 研究位 点分布如图 1 所示.

利用彼得森采泥器采集滇池表层 $10 \mathrm{~cm}$ 沉积 物样品, 样品装入塑料密封袋排出空气密封, 及 时送回实验室冷冻干燥, 然后研磨过 200 目篮 备用.

\section{3 测定方法}

沉积物中 $\mathrm{NH}_{4}^{+}-\mathrm{N}$ 含量采用浸提后静酚蓝比 色法测定; $\mathrm{NO}_{3}^{-}-\mathrm{N}$ 含量采用浸提后紫外分光光度 法测定; $\mathrm{NO}_{2}^{-}-\mathrm{N}$ 含量采用浸提后重氮偶氮分光光 度法测定 ${ }^{[9]}$.

沉积物 $\mathrm{NH}_{4}^{+}-\mathrm{N}$ 的吸附动力学实验 ${ }^{[4]}$ : 称取沉 积物干样 $0.5000 \mathrm{~g}$ 若干份, 置于 $100 \mathrm{ml}$ 聚乙烯离 心管中, 分别加人 $10 \mathrm{mg} / \mathrm{L}$ 的 $\mathrm{NH}_{4} \mathrm{Cl}$ 溶液 $50 \mathrm{ml}$, 在室温 $(25 \pm 1)^{\circ} \mathrm{C}$ 下振荡 (200 转 $/ \mathrm{min}$ ). 每隔一定 时间 $(5 、 10 、 30 、 60 、 90 、 120 、 150$ 和 $180 \mathrm{~min})$ 取出 离心管, 在 5000 转 $/ \mathrm{min}$ 条件下离心 $10 \mathrm{~min}$, 过 滤, 采用标准方法取上清液测定 $\mathrm{NH}_{4}^{+}-\mathrm{N}$ 浓度 (平 衡浓度). 根据起始浓度与平衡浓度之差扣除空 白, 计算沉积物吸附 $\mathrm{NH}_{4}^{+}-\mathrm{N}$ 的量. 以上实验在相 同的条件下作 3 个平行, 相对误差 $<5 \%$.

沉积物 $\mathrm{NH}_{4}^{+}-\mathrm{N}$ 的吸附热力学实验 ${ }^{[4]}$ : 称取沉 
积物干样 $0.5000 \mathrm{~g}$ 若干份, 置于 $100 \mathrm{ml}$ 聚乙烯离心管中, 分别加人 $50 \mathrm{ml}$ 不同浓度的 $\mathrm{NH}_{4} \mathrm{Cl}$ 溶液, 其浓度范 围分别设置低浓度 $(0 、 0.4 、 0.8 、 1.2 、 2 、 5 \mathrm{mg} / \mathrm{L})$ 和高浓度 $(20 、 60 、 80 、 120 、 150 、 200 \mathrm{mg} / \mathrm{L}) 2$ 组系列, 在室温 $(25 \pm 1)^{\circ} \mathrm{C}$ 下振荡 $(200$ 转 $/ \mathrm{min}) 2 \mathrm{~h}$ 后, 取出离心管, 在 5000 转 $/ \mathrm{min}$ 条件下离心 $5 \mathrm{~min}$, 过滤, 采用标准方法取 上清液测定 $\mathrm{NH}_{4}^{+}-\mathrm{N}$ 浓度 (平衡浓度). 根据起始浓度与平衡浓度之差扣除空白, 计算沉积物吸附 $\mathrm{NH}_{4}^{+}-\mathrm{N}$ 的量. 以上实验在相同的条件下作 3 个平行, 相对误差 $<5 \%$.

实验数据分别采用 Excel 2007、SPSS 16.0 以及 ArcGIS 软件进行统计检验、多元回归和作图.

\section{2 结果与分析}

\section{1 滇池表层沉积物中不同形态氮含量的分布特征}

滇池表层沉积物总氮 ( TN) 含量介于 $1596.25 \sim 5558.50 \mathrm{mg} / \mathrm{kg}$ 之间, 平均值为 $3307.26 \mathrm{mg} / \mathrm{kg}$. 长江中下 游湖泊沉积物中 TN 含量在 $770.00 \sim 2630.00 \mathrm{mg} / \mathrm{kg}$ 之间 ${ }^{[10]}$, 洱海沉积物中 TN 含量在 $2084.40 \sim$ $6515.30 \mathrm{mg} / \mathrm{kg}$ 之间 ${ }^{[11]}$, 滇池沉积物 TN 含量与高原湖泊洱海相当, 是长江中下游湖泊的 2.5 倍左右, 表明其 $\mathrm{TN}$ 含量处于较高水平.

与 TN 相比, 不同形态氮更能有效表征氮在湖泊富营养化中的作用. 滇池沉积物中 $\mathrm{NH}_{4}^{+}-\mathrm{N}$ 含量最高, $\mathrm{NO}_{3}^{-}-\mathrm{N}$ 含量次之,亚硝态氮 $\left(\mathrm{NO}_{2}^{-}-\mathrm{N}\right.$ ) 含量最低 (表 1).

表 12013 年滇池沉积物中不同形态氮含量 $(\mathrm{mg} / \mathrm{kg})$

Tab.1 Content of different forms of nitrogen in the sediment samples in Lake Dianchi

\begin{tabular}{|c|c|c|c|c|}
\hline 区域 & 参数 & $\mathrm{NH}_{4}^{+}-\mathrm{N}$ & $\mathrm{NO}_{3}^{-}-\mathrm{N}$ & $\mathrm{NO}_{2}^{-}-\mathrm{N}$ \\
\hline \multirow[t]{3}{*}{ 草海 } & 平均值 & 242.30 & 161.78 & 0.85 \\
\hline & 最小值 & 135.70 & 9.90 & 0.40 \\
\hline & 最大值 & 320.97 & 272.41 & 1.19 \\
\hline \multirow[t]{3}{*}{ 外海 } & 平均值 & 337.30 & 171.55 & 1.03 \\
\hline & 最小值 & 34.66 & 19.11 & 0.11 \\
\hline & 最大值 & 667.82 & 836.40 & 8.76 \\
\hline
\end{tabular}

滇池表层沉积物中 TN 含量相对较高的区域分别分布在草海、外海北岸、湖心、海口及外海南岸, $\mathrm{NH}_{4}^{+}-\mathrm{N}$ 、 $\mathrm{NO}_{3}^{-}-\mathrm{N}$ 和 $\mathrm{NO}_{2}^{-}-\mathrm{N}$ 含量分布与 $\mathrm{TN}$ 具有相似性, 即在靠近昆明主城区域、湖心区域以及海口区域含量相对较高 (图 2). 草海和外海北岸接近昆明主城, 外源输人累积是其主要影响因素; 湖心区域水深较深, 扰动较小, 有 利于不同形态氮素的沉降蓄积; 海口区域的螳螂川是滇池唯一出口, 水体中的氮素随着湖水流出, 大量汇集 于此, 沉降进人底泥; 靠近晋宁县的外海南部区域为农业相对密集区域, 大量氮肥随雨水径流、水土流失等 是影响沉积物氮素水平的重要因素.

\section{2 滇池表层沉积物中 $\mathrm{NH}_{4}^{+}-\mathrm{N}$ 的吸附/解吸特征}

2.2.1 滇池表层沉积物 $\mathrm{NH}_{4}^{+}-\mathrm{N}$ 的吸附动力学特征 沉积物 $\mathrm{NH}_{4}^{+}-\mathrm{N}$ 的吸附是一个复杂的动力学过程, 通常包 括快吸附和慢吸附两个过程. 滇池不同区域表层沉积物对 $\mathrm{NH}_{4}^{+} \mathrm{-N}$ 的吸附基本上都是在前 $2 \mathrm{~h}$ 之内随着时间 的推移, 吸附量呈增长趋势, 且吸附速率较大; 之后吸附量不再随时间变化而变化, 达到吸附平衡 (图 3). 这 与前人的研究结果一致 ${ }^{[12-14]}$.

滇池表层沉积物对 $\mathrm{NH}_{4}^{+}-\mathrm{N}$ 的最大吸附速率均发生在 $0 \sim 5 \mathrm{~min}$ 内. 所有采样点表层沉积物对 $\mathrm{NH}_{4}^{+}-\mathrm{N}$ 的吸 附速率在 $5 \mathrm{~min}$ 之后逐渐降低, 与 $5 \mathrm{~min}$ 之内的吸附速率相差几倍至几十倍. 而不同采样点表层沉积物对 $\mathrm{NH}_{4}^{+}-\mathrm{N}$ 的吸附速率的差异主要显示在前 5 min 之内 (表 2).

滇池不同区域表层沉积物对 $\mathrm{NH}_{4}^{+}-\mathrm{N}$ 的平均最大吸附速率表现为: 外海南部 $(34.62 \mathrm{mg} /(\mathrm{kg} \cdot \min ))>$ 湖 心区 $(27.15 \mathrm{mg} /(\mathrm{kg} \cdot \mathrm{min}))>$ 外海北部 $(23.44 \mathrm{mg} /(\mathrm{kg} \cdot \mathrm{min}))>$ 草海 $(21.22 \mathrm{mg} /(\mathrm{kg} \cdot \min ))$ (图 4). 不同区 域表层沉积物对 $\mathrm{NH}_{4}^{+}-\mathrm{N}$ 的最大吸附速率差异较大, 滇池外海大部分区域均高于草海, 这是由于有机质含量 较草海低,使得有机质对沉积物中 $\mathrm{NH}_{4}^{+}-\mathrm{N}$ 交换的吸附点位干扰较少, 因此整个外海沉积物对 $\mathrm{NH}_{4}^{+}-\mathrm{N}$ 的吸附 速率较高 ${ }^{[15-16]}$. 

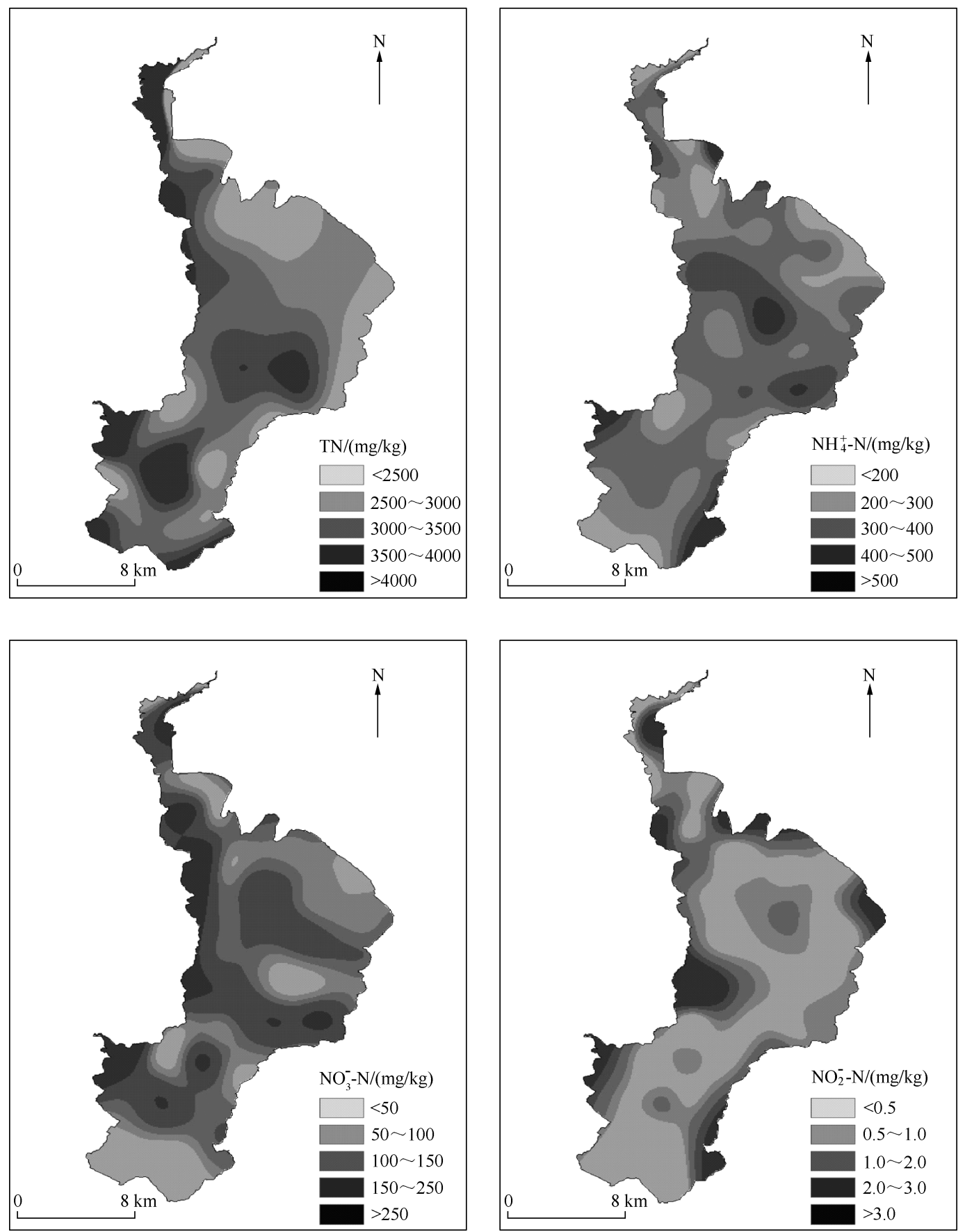

图 2 滇池表层沉积物不同形态氮含量的空间分布

Fig. 2 The spatial distribution of different forms of nitrogen content in the surface sediments of Lake Dianchi 

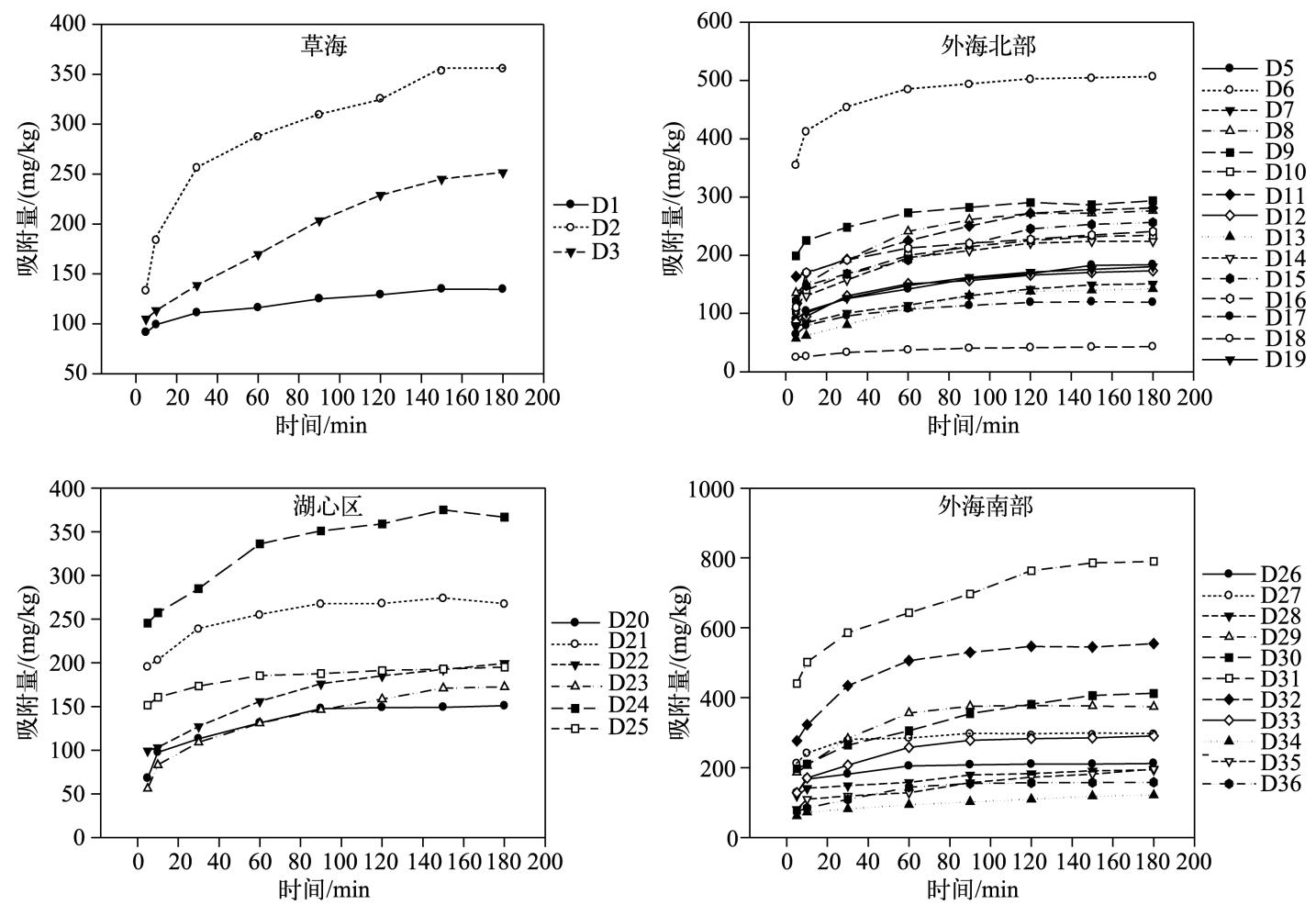

图 3 滇池表层沉积物 $\mathrm{NH}_{4}^{+}-\mathrm{N}$ 吸附动力学曲线

Fig.3 Adsorption kinetic curves of $\mathrm{NH}_{4}^{+}-\mathrm{N}$ in the surface sediments of Lake Dianchi

表 2 不同时间段滇池表层沉积物对 $\mathrm{NH}_{4}^{+}-\mathrm{N}$ 的吸附速率 $(\mathrm{mg} /(\mathrm{kg} \cdot \mathrm{min}))$

Tab.2 Adsorption rate of $\mathrm{NH}_{4}^{+}-\mathrm{N}$ in the surface sediments of Lake Dianchi in different intervals

\begin{tabular}{ccrrrrrrrrc}
\hline \multirow{2}{*}{ 区域 } & 参数 & \multicolumn{7}{c}{$t / \mathrm{min}$} \\
\cline { 3 - 10 } & & $0 \sim 5$ & $5 \sim 10$ & $10 \sim 30$ & $30 \sim 60$ & $60 \sim 90$ & $90 \sim 120$ & $120 \sim 150$ & $150 \sim 180$ \\
\hline \multirow{2}{*}{ 草海 } & 最小值 & 18.07 & 2.35 & 0.45 & 0.27 & 0.20 & 0.17 & 0.13 & 0.02 \\
& 最大值 & 26.61 & 12.10 & 2.63 & 1.37 & 0.83 & 0.64 & 0.49 & 0.41 \\
& 平均值 & 21.22 & 8.05 & 1.58 & 0.87 & 0.59 & 0.48 & 0.33 & 0.27 \\
外海北部 & 最小值 & 4.90 & 2.30 & 0.35 & 0.14 & 0.12 & 0.08 & 0.03 & 0.01 \\
& 最大值 & 70.84 & 11.90 & 2.07 & 1.02 & 0.67 & 0.57 & 0.28 & 0.20 \\
& 平均值 & 23.44 & 6.94 & 1.22 & 0.64 & 0.40 & 0.29 & 0.14 & 0.08 \\
湖心区 & 最小值 & 11.17 & 3.77 & 0.64 & 0.16 & 0.08 & 0.04 & 0.03 & 0.01 \\
& 最大值 & 49.07 & 10.37 & 1.38 & 0.73 & 0.51 & 0.42 & 0.42 & 0.23 \\
& 平均值 & 27.15 & 5.97 & 1.01 & 0.53 & 0.41 & 0.26 & 0.20 & 0.08 \\
外海南部 & 最小值 & 12.30 & 4.20 & 0.49 & 0.25 & 0.11 & 0.06 & 0.03 & 0.02 \\
& 最大值 & 88.09 & 18.21 & 3.88 & 2.40 & 1.42 & 1.26 & 1.07 & 1.14 \\
& 平均值 & 34.62 & 9.74 & 1.92 & 0.86 & 0.55 & 0.38 & 0.28 & 0.22 \\
\hline
\end{tabular}

本研究利用修正的 Elovich 模型 ${ }^{[17-18]}$ 对 $\mathrm{NH}_{4}^{+}-\mathrm{N}$ 吸附动力学过程进行拟合, 从而进一步明确滇池沉积物 对 $\mathrm{NH}_{4}^{+}-\mathrm{N}$ 的吸附特征:

$$
q=a+b \cdot \ln t
$$




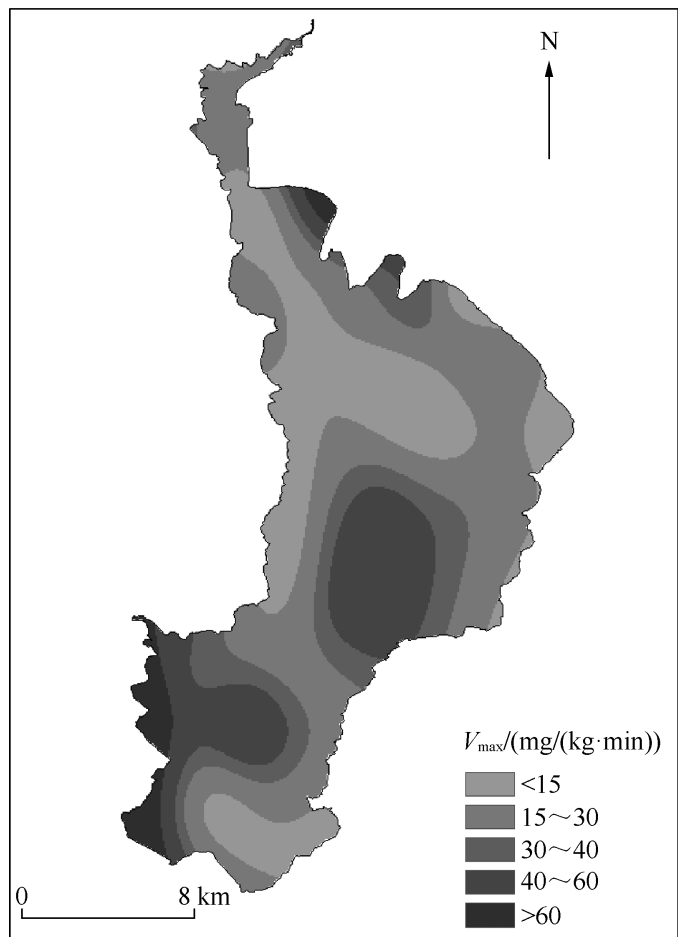

图 4 滇池表层沉积物对 $\mathrm{NH}_{4}^{+}-\mathrm{N}$ 的最大吸附速率

Fig.4 The maximum adsorption rate of $\mathrm{NH}_{4}^{+}-\mathrm{N}$ in the surface sediments of Lake Dianchi

表 3 滇池表层沉积物吸附 $\mathrm{NH}_{4}^{+}-\mathrm{N}$

的 Elovich 模型拟合参数

Tab.3 The fitting parameters of the Elovich

Model of $\mathrm{NH}_{4}^{+}-\mathrm{N}$ adsorption in the

surface sediments of Lake Dianchi

\begin{tabular}{crcc}
\hline 区域 & $a$ & $b$ & $R^{2}$ \\
\hline 草海 & 46.89 & 39.36 & 0.99 \\
外海北部 & 78.65 & 28.39 & 0.98 \\
湖心区 & 100.48 & 25.14 & 0.97 \\
外海南部 & 116.23 & 41.40 & 0.97 \\
\hline
\end{tabular}

附一解吸平衡零点浓度, $E N C_{0}=N A N / K_{\mathrm{d}}$.

滇池表层沉积物 $\mathrm{NH}_{4}^{+}-\mathrm{N}$ 的吸附一解吸平衡浓度 $E N C_{0}$ 最大值为 $9.62 \mathrm{mg} / \mathrm{L}$, 最小值为 $1.40 \mathrm{mg} / \mathrm{L}($ 表 4), 上覆水中 $\mathrm{NH}_{4}^{+}-\mathrm{N}$ 的均值为 $1.56 \mathrm{mg} / \mathrm{L}$. 根据历史研究 ${ }^{[21-22]}$, 当上覆水中 $\mathrm{NH}_{4}^{+}$离子浓度低于沉积物中 $\mathrm{NH}_{4}^{+}$离子 浓度时, 沉积物就会起到 “源” 的作用, 反之就会起到 “汇” 的作用.相关研究表明 ${ }^{[23]}$, 当湖泊上覆水中氮浓度 大于 $0.2 \mathrm{mg} / \mathrm{L}$ 时, 就可以认为该湖泊水体达到富营养化水平, 而滇池表层沉积物 $\mathrm{NH}_{4}^{+}-\mathrm{N}$ 的 $E N C_{0}$ 最小值为 $1.40 \mathrm{mg} / \mathrm{L}$, 远超过 $0.2 \mathrm{mg} / \mathrm{L}$, 表明当滇池水体处于富营养化水平时, 沉积物中 $\mathrm{NH}_{4}^{+}-\mathrm{N}$ 仍可能向上覆水中释 放, 从而加重滇池水体污染.
式中, $q$ 为沉积物吸附 $\mathrm{NH}_{4}^{+}-\mathrm{N}$ 的量 $(\mathrm{mg} / \mathrm{kg}) ; t$ 为 时间 ( $\min ) ; a 、 b$ 为常数, $a$ 为初始吸附率, $b$ 为吸 附系数, 其大小标志着沉积物吸附 $\mathrm{NH}_{4}^{+}-\mathrm{N}$ 的 强度.

拟合结果(表 3) 表明,滇池表层沉积物对 $\mathrm{NH}_{4}^{+}-\mathrm{N}$ 的吸附动力学行为很好地符合修正的 Elovich 模 型, 拟合曲线 $R^{2}$ 值高于 0.90 , 均达到极显著水平 $(P<0.01)$. 同时, 不同污染水平沉积物的 $\mathrm{NH}_{4}^{+}-\mathrm{N}$ 吸 附参数间差别较大, 说明滇池表层沉积物吸附 $\mathrm{NH}_{4}^{+}-\mathrm{N}$ 的过程十分复杂, 受到多种因素的影响.

2.2.2 滇池表层沉积物对 $\mathrm{NH}_{4}^{+}-\mathrm{N}$ 的吸附一解吸平衡 浓度 在一系列低浓度范围内 (溶液 $\mathrm{NH}_{4}^{+}-\mathrm{N}$ 初始 浓度 $<5 \mathrm{mg} / \mathrm{L}$ ), 滇池表层沉积物对 $\mathrm{NH}_{4}^{+}-\mathrm{N}$ 的吸附 量与平衡溶液中 $\mathrm{NH}_{4}^{+}-\mathrm{N}$ 浓度呈良好的线性关系, 通 过改变溶液中氮的浓度, 对沉积物 $\mathrm{NH}_{4}^{+}-\mathrm{N}$ 的吸附量 和初始溶液浓度进行线性回归, 表明滇池不同采样 点表层沉积物对 $\mathrm{NH}_{4}^{+}-\mathrm{N}$ 均存在不同程度的解吸现 象, 即在 $\mathrm{NH}_{4}^{+}-\mathrm{N}$ 初始浓度较低的情况下, 沉积物中 $\mathrm{NH}_{4}^{+}-\mathrm{N}$ 处于释放状态, 而后随着 $\mathrm{NH}_{4}^{+}-\mathrm{N}$ 浓度的增 加, 沉积物开始吸附 $\mathrm{NH}_{4}^{+}-\mathrm{N}$, 并且 $\mathrm{NH}_{4}^{+}-\mathrm{N}$ 吸附量随 液相 $\mathrm{NH}_{4}^{+}-\mathrm{N}$ 平衡浓度的增大而增大, 滇池表层沉积 物对 $\mathrm{NH}_{4}^{+}-\mathrm{N}$ 的吸附量与 $\mathrm{NH}_{4}^{+}-\mathrm{N}$ 的初始浓度大致呈 线性关系, 并且在低浓度下表现出很好的吸附/解 吸特征 (图 5), 这同前人的研究成果一致 ${ }^{[19]}$.

沉积物对 $\mathrm{NH}_{4}^{+}-\mathrm{N}$ 吸附量与 $\mathrm{NH}_{4}^{+}-\mathrm{N}$ 吸附平衡浓 度呈良好的线性关系, 可用 Henry 方程 ${ }^{[20]}$ 很好地 拟合:

$$
Q=N A N+K_{\mathrm{d}} \cdot E N C_{0}
$$

式中, $Q$ 为 $\mathrm{NH}_{4}^{+}-\mathrm{N}$ 的吸附-释放量; $N A N$ 为本底吸 附 $\mathrm{NH}_{4}^{+}-\mathrm{N}$ 量; $K_{\mathrm{d}}$ 为线性分配系数, 代表了沉积物与 $\mathrm{NH}_{4}^{+}$的亲和力及沉积物的缓冲强度; $E N C_{0}$ 为吸附平 衡时溶液浓度; 这些曲线与吸附量为 0 的直线的交 点 $X_{0}$ 表示沉积物与水体达到吸附一解吸平衡时溶液 中 $\mathrm{NH}_{4}^{+}$离子的浓度为 $E N C_{0}$, 即 $Q=0 \mathrm{mg} / \mathrm{kg}$ 时为吸 

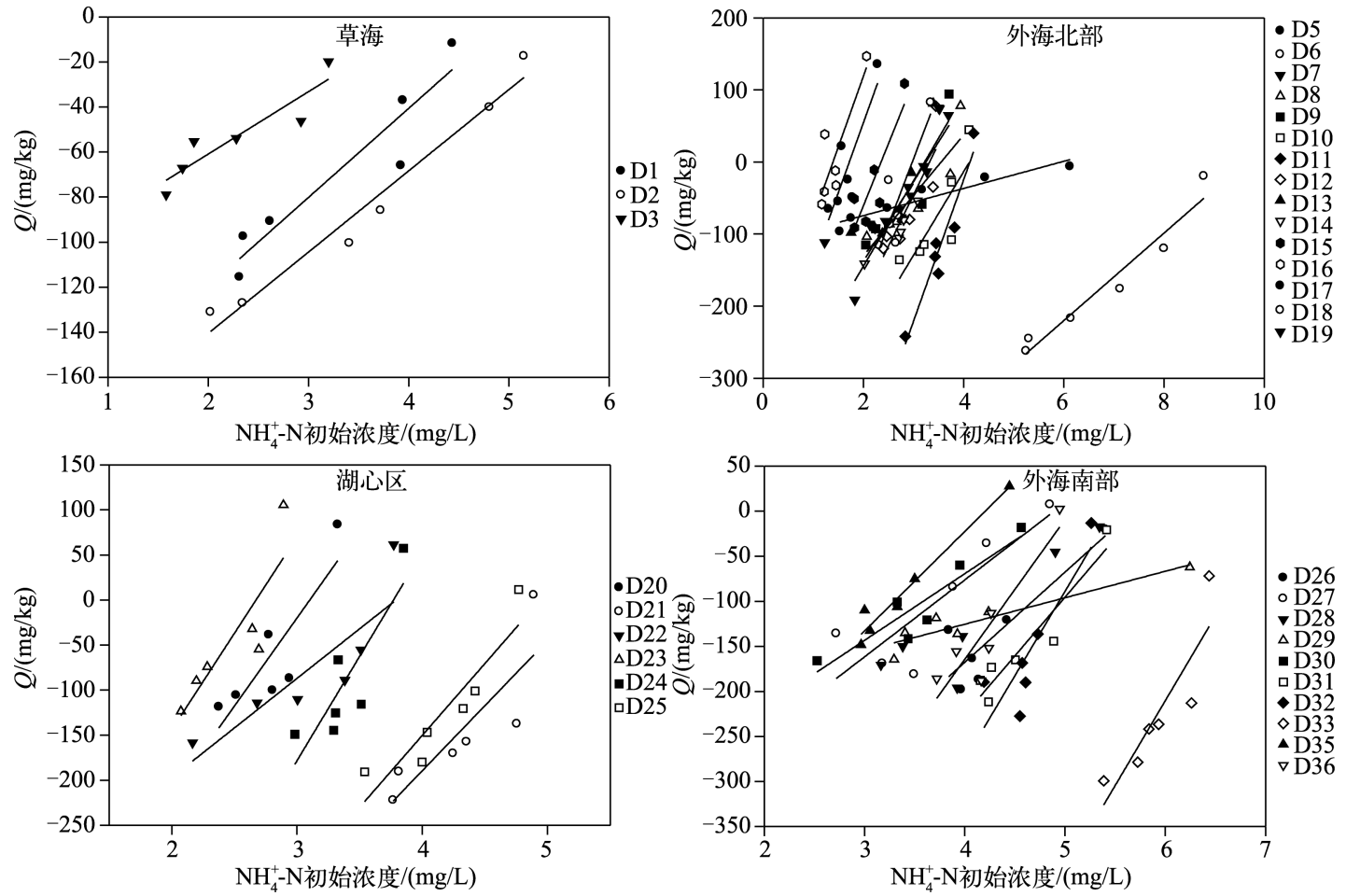

图 5 滇池表层沉积物对 $\mathrm{NH}_{4}^{+}-\mathrm{N}$ 的吸附-解吸特征曲线

Fig.5 The adsorption-desorption characteristic curves of $\mathrm{NH}_{4}^{+}-\mathrm{N}$ in the surface sediments of Lake Dianchi

表 4 滇池表层沉积物对 $\mathrm{NH}_{4}^{+}-\mathrm{N}$ 的吸附-释放特征参数

Tab.4 The adsorption-desorption characteristic parameters of $\mathrm{NH}_{4}^{+}-\mathrm{N}$ in the surface sediments of Lake Dianchi

\begin{tabular}{ccccc}
\hline 区域 & 参数 & $N A N /(\mathrm{mg} / \mathrm{kg})$ & $K_{\mathrm{d}} /(\mathrm{L} / \mathrm{kg})$ & $E N C_{0} /(\mathrm{mg} / \mathrm{L})$ \\
\hline 草海 & 最小值 & 116.28 & 27.70 & 4.20 \\
& 最大值 & 212.65 & 39.57 & 5.89 \\
& 平均值 & 175.92 & 34.45 & 5.04 \\
外海北部 & 最小值 & 116.28 & 27.70 & 1.40 \\
& 最大值 & 810.19 & 196.29 & 9.62 \\
& 平均值 & 404.52 & 127.80 & 3.56 \\
湖心区 & 最小值 & 116.28 & 27.70 & 1.40 \\
& 最大值 & 810.19 & 196.29 & 9.62 \\
& 平均值 & 305.97 & 75.59 & 4.95 \\
外海南部 & 最小值 & 242.93 & 29.39 & 4.20 \\
& 最大值 & 1340.32 & 188.36 & 8.27 \\
& 平均值 & 638.30 & 113.54 & 5.71 \\
\hline
\end{tabular}

沉积物 $\mathrm{NH}_{4}^{+}-\mathrm{N}$ 吸附实验测得的 $\mathrm{NH}_{4}^{+}-\mathrm{N}$ 吸附量实际上仅是表观吸附量, 即吸附量应包括本底结合在沉 积物上可以解吸的 $\mathrm{NH}_{4}^{+}-\mathrm{N}$ 量和真正在吸附实验中被吸附的 $\mathrm{NH}_{4}^{+}-\mathrm{N}$. 当沉积物对 $\mathrm{NH}_{4}^{+}-\mathrm{N}$ 的释放量等于吸附实 验中被吸附的 $\mathrm{NH}_{4}^{+}-\mathrm{N}$ 量时, 沉积物对 $\mathrm{NH}_{4}^{+}-\mathrm{N}$ 的表观吸附量为 0 , 此时溶液的 $\mathrm{NH}_{4}^{+}-\mathrm{N}$ 浓度即为沉积物的吸 附/解吸平衡浓度. 结合相关性研究, 根据表 4 得到滇池表层沉积物的 $N A N$ 值介于 $116.28 \sim 1340.32 \mathrm{mg} / \mathrm{kg}$, 变幅较大, 平均值为 $500.13 \mathrm{mg} / \mathrm{kg}$. 不同区域表层沉积物 $N A N$ 平均值表现为: 湖心区 $(670.99 \mathrm{mg} / \mathrm{kg})>$ 外海南 
表 5 不同湖泊沉积物对 $\mathrm{NH}_{4}^{+}-\mathrm{N}$ 的吸附/ 解吸特征参数 ${ }^{[24]}$

Tab.5 The adsorption-desorption characteristic parameters of $\mathrm{NH}_{4}^{+}-\mathrm{N}$ in the surface sediments of different lakes

\begin{tabular}{ccc}
\hline 湖泊(年份) & $N A N /(\mathrm{mg} / \mathrm{kg})$ & $E N C_{0} /(\mathrm{mg} / \mathrm{L})$ \\
\hline 滇池 $(2013$ 年 $)$ & 500.13 & 4.39 \\
太湖 $(2003$ 年) & 39.09 & 1.78 \\
鄱阳湖 $(2003$ 年) & 21.54 & 1.20 \\
洪泽湖 $(2003$ 年) & 31.86 & 1.22 \\
\hline
\end{tabular}

岸 $(638.50 \mathrm{mg} / \mathrm{kg})>$ 外海北岸 $(404.52 \mathrm{mg} / \mathrm{kg})>$ 草 海 $(175.92 \mathrm{mg} / \mathrm{kg})$.

长江中下游浅水湖泊沉积物对 $\mathrm{NH}_{4}^{+}-\mathrm{N}$ 的吸附 研究 ${ }^{[4]}$ 表明, 本底态吸附量与湖泊的污染程度密切 相关, 即湖泊污染越严重, 其沉积物对 $\mathrm{NH}_{4}^{+}-\mathrm{N}$ 本 底态吸附量越大. 滇池表层沉积物 $N A N$ 远远大于其 他湖泊 (表 5), 说明滇池湖体污染较其他湖泊严 重, 并且滇池表层沉积物的 $E N C_{0}$ 是其他湖泊的 2 3 倍, 沉积物中 $\mathrm{NH}_{4}^{+}-\mathrm{N}$ 的释放风险同样很高.

2.2.3 滇池表层沉积物对 $\mathrm{NH}_{4}^{+}-\mathrm{N}$ 的吸附等温拟合

当模拟实验中溶液 $\mathrm{NH}_{4}^{+}-\mathrm{N}$ 的初始浓度在 $5 \sim$

$200 \mathrm{mg} / \mathrm{kg}$ 范围内时, 滇池不同区域表层沉积物对 $\mathrm{NH}_{4}^{+}-\mathrm{N}$ 的吸附量都是随液相 $\mathrm{NH}_{4}^{+}-\mathrm{N}$ 平衡浓度的增大而增 大. 在低浓度区, 各样点沉积物对 $\mathrm{NH}_{4}^{+}-\mathrm{N}$ 的吸附量与 $\mathrm{NH}_{4}^{+}-\mathrm{N}$ 的初始浓度基本呈线性关系, 但 $\mathrm{NH}_{4}^{+}-\mathrm{N}$ 吸附量 差异较小; 在高浓度区, 各样点沉积物对 $\mathrm{NH}_{4}^{+}-\mathrm{N}$ 的吸附都变得缓慢, 但 $\mathrm{NH}_{4}^{+}-\mathrm{N}$ 差异较为明显(图 6).
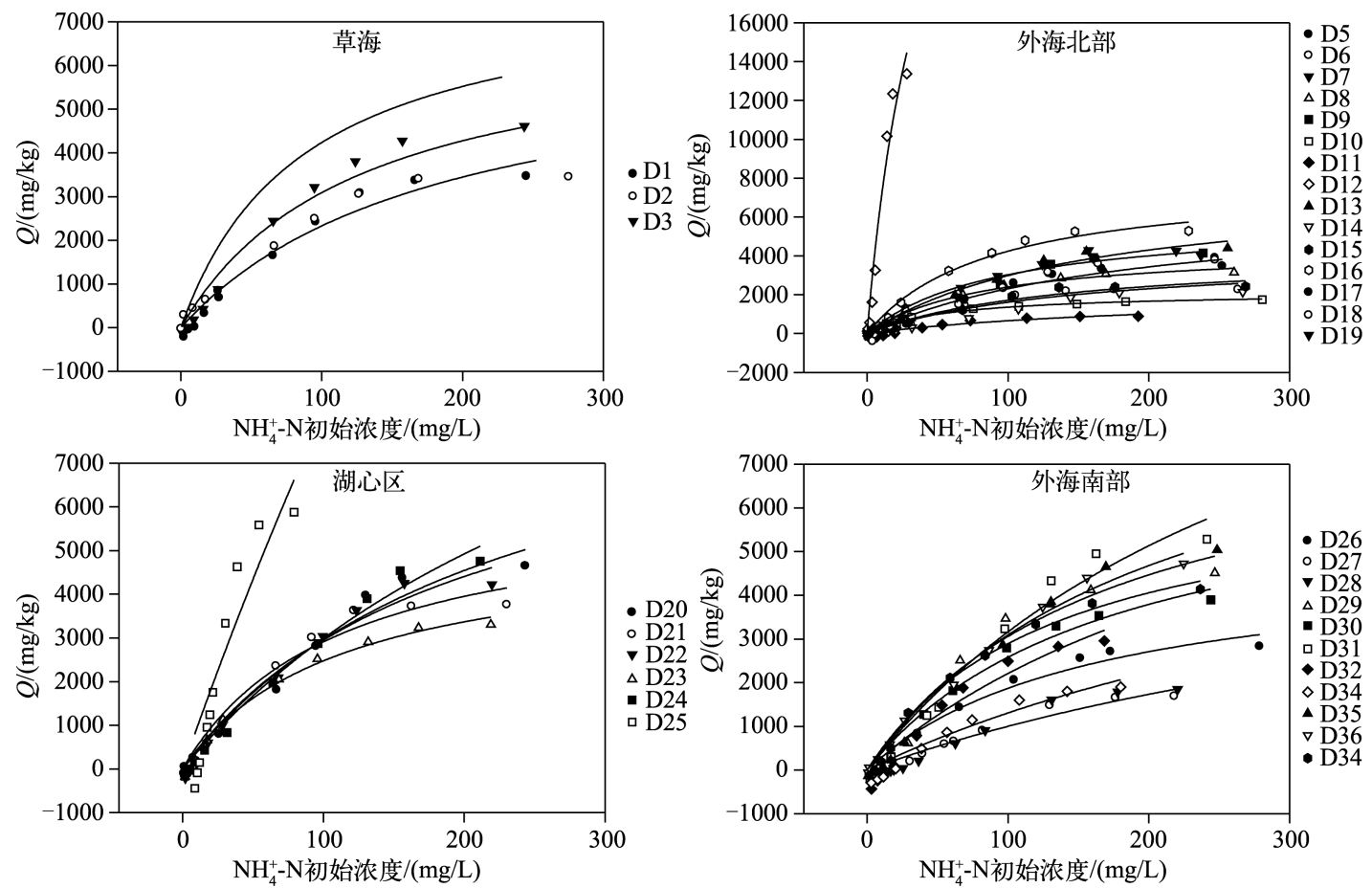

图 6 滇池表层沉积物对 $\mathrm{NH}_{4}^{+}-\mathrm{N}$ 的吸附等温线

Fig. 6 The adsorption isotherm of $\mathrm{NH}_{4}^{+}-\mathrm{N}$ in the surface sediments of Lake Dianchi

利用扩展的 Langmuir 吸附等温方程对滇池表层沉积物进行拟合 ${ }^{[25-26]}$, 计算得到 $\mathrm{NH}_{4}^{+}-\mathrm{N}$ 的最大吸附量 及吸附效率, 拟合结果较好, 均达到显著水平 $(P<0.0001)$.

$$
Q=Q_{\max } \cdot K \cdot C /(1+K \cdot C)
$$

式中, $Q$ 为沉积物对 $\mathrm{NH}_{4}^{+}$的吸附容量; $Q_{\text {max }}$ 为最大吸附容量, 是反映沉积物吸附 $\mathrm{NH}_{4}^{+}-\mathrm{N}$ 的容量因子, 是沉积物 对 $\mathrm{NH}_{4}^{+}-\mathrm{N}$ 吸附的数量指标; $C$ 为吸附平衡浓度; $K$ 为平衡吸附系数, 表示沉积物胶体与氮的亲和能力, 是反

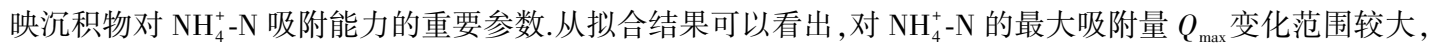


在 $2135.59 \sim 66253.21 \mathrm{mg} / \mathrm{kg}$ 之间, 平均值为 $10155.46 \mathrm{mg} / \mathrm{kg}$ (表 6).

从不同区域的 $Q_{\text {max }}$ 分布 (图 7) 可以看出, 滇 池不同区域表层沉积物对 $\mathrm{NH}_{4}^{+}-\mathrm{N}$ 的吸附量差异 较大, 其中湖心区域最大吸附量最高, 这可能是 由于该区域水深较深,沉积物受外界干扰低, 经 过多年的汇集形成厚度较深的淤泥层, 且水生植 物和藻类含量较低 ${ }^{[27]}$, 因缺少初级生产者的消耗 利用,导致 $\mathrm{NH}_{4}^{+}-\mathrm{N}$ 更易于被沉积物吸附固定 ${ }^{[28]}$.

滇池表层沉积物对 $\mathrm{NH}_{4}^{+}-\mathrm{N}$ 的吸附效率 $K$ 值 介于 $0.0007 \sim 0.0241 \mathrm{~L} / \mathrm{mg}$ 之间, 平均值为 $0.0062 \mathrm{~L} / \mathrm{mg}$, 不同区域平均 $K$ 值表现为: 外海北 部 $(0.0082 \mathrm{~L} / \mathrm{mg})>$ 草海 $(0.0072 \mathrm{~L} / \mathrm{mg})>$ 湖心区 $(0.0052 \mathrm{~L} / \mathrm{mg})>$ 外海南部 $(0.0040 \mathrm{~L} / \mathrm{mg})$. 其中, 以滇池草海及外海北部湖区表层沉积物对 $\mathrm{NH}_{4}^{+}-\mathrm{N}$ 的吸附效率较高. 滇池草海及外海北部湖区是滇 池疏浚工程的重点区域, 疏浚工程设计疏浚沉 积物的厚度为 $15 \sim 50 \mathrm{~cm}$, 而草海和外海北部沉 积物的污染层平均为 $26.40 \mathrm{~cm}$, 过渡层平均为 $70.20 \mathrm{~cm}$, 疏浚工程基本已将污染层的沉积物转 移出湖体, 新产生的沉积物 - 水界面 $\mathrm{NH}_{4}^{+}-\mathrm{N}$ 含量 大幅度降低,打破了原有界面氮素的平衡浓度, 浓度梯度使得沉积物对水体中 $\mathrm{NH}_{4}^{+}-\mathrm{N}$ 吸附能力 有所增强.

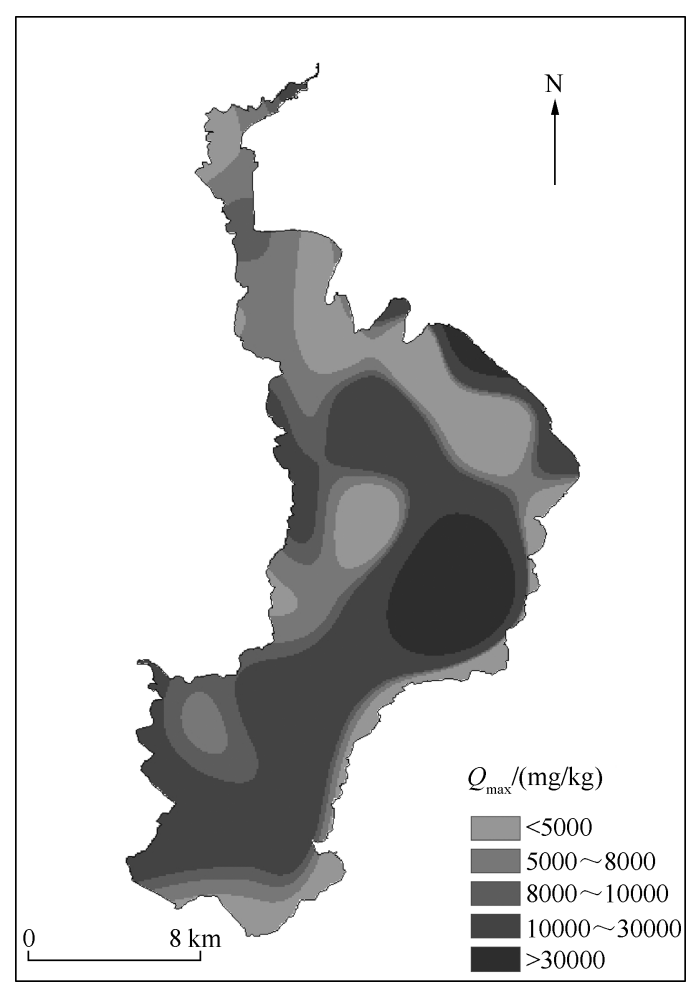

图 7 滇池表层沉积物对 $\mathrm{NH}_{4}^{+}-\mathrm{N}$ 的最大吸附量的分布

Fig.7 The distribution of the maximum adsorption quantity of $\mathrm{NH}_{4}^{+}-\mathrm{N}$ in the surface sediments of Lake Dianchi

表 6 滇池表层沉积物对 $\mathrm{NH}_{4}^{+}-\mathrm{N}$ 的吸附等温线特征参数

Tab.6 Adsorption isotherm characteristic parameters of $\mathrm{NH}_{4}^{+}-\mathrm{N}$ in the surface sediments of Lake Dianchi

\begin{tabular}{cccc}
\hline 区域 & 参数 & $K /(\mathrm{L} / \mathrm{mg})$ & $Q_{\max } /(\mathrm{mg} / \mathrm{kg})$ \\
\hline 草海 & 最小值 & 0.0056 & 5099.06 \\
& 最大值 & 0.0097 & 8093.91 \\
平均值 & 0.0072 & 6577.41 \\
外海北部 & 最小值 & 0.0027 & 2135.59 \\
& 最大值 & 0.0241 & 35774.53 \\
& 平均值 & 0.0082 & 8233.99 \\
湖心区 & 最小值 & 0.0014 & 5246.07 \\
& 最大值 & 0.0090 & 66253.21 \\
& 平均值 & 0.0052 & 18383.80 \\
外海南部 & 最小值 & 0.0007 & 4883.16 \\
& 最大值 & 0.0074 & 15342.43 \\
& 平均值 & 0.0040 & 9263.29 \\
\hline
\end{tabular}

\section{3 滇池表层沉积物吸附 $\mathrm{NH}_{4}^{+}-\mathrm{N}$ 的特征与其理化性质的相关关系}

湖泊沉积物的理化性质对其 $\mathrm{NH}_{4}^{+}-\mathrm{N}$ 的释放有着极为重要的影响 ${ }^{[29]}$, 为了深人探讨滇池表层沉积物对 $\mathrm{NH}_{4}^{+}-\mathrm{N}$ 吸附-解吸特征的影响因素, 对其吸附特征参数与其主要的理化性质进行相关分析 (表 7), 结果表明, $E N C_{0}$ 与沉积物中 $\mathrm{TN} 、 \mathrm{NH}_{4}^{+}-\mathrm{N}$ 含量均呈显著正相关 $(P<0.05)$, 这是因为沉积物中活跃氮素含量的增加会促 
进 $\mathrm{NH}_{4}^{+}-\mathrm{N}$ 的释放, 从而降低沉积物的吸附效率 ${ }^{[30]} ; N A N$ 与有机质总量呈显著负相关关系 $(P<0.05)$, 与其他 指标相关性未达到显著水平 $(P>0.05)$, 这是因为有机质会占据和阻塞沉积物中 $\mathrm{NH}_{4}^{+}-\mathrm{N}$ 交换的吸附点, 从而 导致沉积物对 $\mathrm{NH}_{4}^{+}-\mathrm{N}$ 的吸附能力降低 ${ }^{[15-16,31]}$.

表 7 滇池表层沉积物 $\mathrm{NH}_{4}^{+}-\mathrm{N}$ 的吸附特征参数与其理化指标的相关系数

Tab.7 Correlation between the adsorption characteristic parameters and the physical and chemical properties of $\mathrm{NH}_{4}^{+}-\mathrm{N}$ in the surface sediments of Lake Dianchi

\begin{tabular}{ccccccccc}
\hline 特征参数 & 有机质总量 & $\mathrm{TN}$ & $\mathrm{NH}_{4}^{+}-\mathrm{N}$ & $\mathrm{NO}_{3}^{-}-\mathrm{N}$ & $\mathrm{NO}_{2}^{-}-\mathrm{N}$ & $E N C_{0}$ & $N A N$ & $Q_{\max }$ \\
\hline$E N C_{0}$ & 0.2486 & $0.5001^{*}$ & $0.6160^{*}$ & 0.3096 & -0.0266 & 1 & & \\
$N A N$ & $-0.5007^{*}$ & -0.0810 & 0.3625 & -0.0477 & -0.0559 & 0.2930 & 1 & \\
$Q_{\max }$ & -0.2646 & -0.0635 & 0.0844 & 0.0077 & -0.1435 & -0.0070 & 0.1860 & 1 \\
\hline
\end{tabular}

* 表示 $P<0.05$.

\section{3 结论}

1) 滇池表层沉积物对 $\mathrm{NH}_{4}^{+}-\mathrm{N}$ 的吸附量在前 $2 \mathrm{~h}$ 之内呈增长趋势, 吸附速率较大; $2 \mathrm{~h}$ 之后沉积物吸附 $\mathrm{NH}_{4}^{+}-\mathrm{N}$ 量不随时间变化而变化,基本达到平衡.表层沉积物对 $\mathrm{NH}_{4}^{+}-\mathrm{N}$ 的最大吸附速率均发生在 $0 \sim 5 \mathrm{~min}$ 内; 不同区域样点之间的表层沉积物对 $\mathrm{NH}_{4}^{+} \mathrm{-N}$ 吸附的最大速率差异较大, 主要表现为: 外海南部>湖心区 $>$ 外海 北部>草海.

2) 滇池表层沉积物对 $\mathrm{NH}_{4}^{+}-\mathrm{N}$ 的 $E N C_{0}$ 为 $1.40 \sim 9.62 \mathrm{mg} / \mathrm{L}$, 远高于上覆水中 $\mathrm{NH}_{4}^{+}-\mathrm{N}$ 浓度, 表明沉积物中 $\mathrm{NH}_{4}^{+}-\mathrm{N}$ 具有向上覆水中释放的风险, 沉积物在很长一段时间内起到水体污染 “源” 的作用. 滇池表层沉积物 的 $E N C_{0}$ 是其他湖泊的 2 3 倍, 沉积物中氮的释放风险非常大. 滇池表层沉积物的 $N A N$ 远远大于其他湖泊, 说明滇池湖体污染较其他湖泊严重.

3) 滇池不同区域表层沉积物对 $\mathrm{NH}_{4}^{+}-\mathrm{N}$ 的最大吸附量平均值表现为: 湖心区>外海南部>外海北部>草 海, 不同区域表层沉积物对 $\mathrm{NH}_{4}^{+}-\mathrm{N}$ 的吸附量差异较大; 不同区域吸附 $\mathrm{NH}_{4}^{+}-\mathrm{N}$ 效率的平均值表现为: 外海北 部>草海>湖心区 $>$ 外海南部.

4) 滇池表层沉积物 $E N C_{0}$ 与沉积物中 $\mathrm{TN} 、 \mathrm{NH}_{4}^{+}-\mathrm{N}$ 均呈正相关, 沉积物中大量活性氮素的存在会直接促 进氮素的释放, 造成水质恶化; 而 $N A N$ 和有机质总量呈负相关 $(P<0.05)$, 沉积物若含有大量有机质就会阻 碍沉积物对 $\mathrm{NH}_{4}^{+}-\mathrm{N}$ 的吸附, 破坏沉积物对水质的改善能力. 因此, 在特定区域进行疏浚工程, 清除沉积物中 污染物含量对改善滇池水质具有积极的意义.

\section{4 参考文献}

[ 1 ] Aller RC, Mckin JE, Ullman WJ et al. Early chemical diagenesis, sediment-water solute exchange, and storage of reactive organic matter near the mouth of the Changjiang, East China Sea. Continental Shelf Research, 1985, 4(1/2) : 227-251.

[2] 王而力, 王雅迪, 王嗣淇. 西辽河不同粒级沉积物的氨氮吸附一解吸特征. 环境科学研究, 2012, 25(9): 1016-1023.

[ 3 ] Shen SY, Shu IT, Kemper WD. Equilibrium and kinetic study of ammonium adsorption and fixation in sodium-treated verniculite. Soil Science Society of American Journal, 1997, 61: 1611-1618.

[4] 王 娟, 王圣瑞, 金相灿等. 长江中下游浅水湖泊表层沉积物对氨氮的吸附特征. 农业环境科学学报, 2007,26 (4) : 1224-1229.

[ 5 ] 杨一光, 杨桂华. 滇池自然地理概要. 云南大学学报: 自然科学版, 1985, 7(增刊) : 1-8.

[6] 齐素华, 艾 萍, 王趁义. 滇池的富营养化现状分析及防治对策. 江苏环境科技, 2000, 13(4): 27.

[ 7 ] Liu JL, Wang RM, Hu AB et al. Distribution and bioaccumulation of steroidal and phenolic endocrine disrupting chemicals in wild fish species from Dianchi Lake, China. Environmental Pollution, 2011, 159: 2815-2822.

[ 8 ] Wan X, Pan XJ, Wang B et al. Distributions, historical trends, and source investigation of polychlorinated biphenyls in 
Dianchi Lake, China. Chemosphere, 2011, 85: 361-367.

[ 9 ] 鲍士旦. 土壤农化分析: 第 3 版. 北京: 中国农业出版社, 2000.

[10] 王 娟. 浅水湖泊中氮素分布特征与沉积物氨氮吸附释放机理研究 [学位论文]. 北京: 中国矿业大学, 2007.

[11] 王圣瑞, 何宗健等. 洱海表层沉积物中总氮含量及氨氮的释放特征. 环境科学研究, 2013, 26(3): 256-261.

[12] 胡智瞍, 孙红文, 潭 媛. 湖泊沉积物对 $N$ 和 $\mathrm{P}$ 的吸附特性及影响因素研究. 农业环境科学学报, 2004, 23(6): 1212-1216.

[13] 杨龙元, 蔡启铭, 秦伯强等. 太湖梅梁湾沉积物-水界面氮迁移特征初步研究. 湖泊科学, 1998, 10(4): 41-47. DOI 10. 18307/1998. 0406.

[14] 姜 霞, 王秋娟, 王书航等. 太湖沉积物氮磷吸附/解吸特征分析. 环境科学, 2011, 32(5): 1285-1291.

[15] Swift RS. The effect of adsorbed organic materials on the cation exchange of clay minerals. In: Banin A, Kafkafi U eds. Agrochemicals in soils, 1980: 123-129.

[16] Hedges JI, Keil RG. Sedimentary organic matter preservation: an assessment and speculative synthesis. Marine Chemistry, 1995, 49: 81-115.

[17] Padmesha TVN, Vijayaraghavana K, Sekaranb G et al. Batch and column studies on biosorption of acid dyes on fresh water macro alga Azolla filiculoides. Journal of Hazardous Materials, 2005, 125( 1/2/3) : 121-129.

[18] Wang SR, Jin XC, Pang Y et al. The study on the effect of $\mathrm{pH}$ on phosphate sorption by different trophic Lake sediments. Journal of Colloid and Interface Science, 2005, 285: 448-457.

[19] 王圣瑞, 金相灿, 赵海朝等. 长江中下游浅水湖泊沉积物对磷的吸附特征. 环境科学, 2005, 26 (3): 38-43.

[20] Jin X, Wang S, Pang Y et al. The adsorption of phosphate on different trophic lake sediments. Colloids and Surfaces A: Physicochemical \& Engineering Aspects, 2005, 254: 241-248.

[21] 翟丽华, 刘鸿亮, 席北斗. 农业源头沟渠沉积物氮磷吸附特性研究. 农业环境科学学报, 2008, 27 (4): 1359-1363.

[22] 杨洪美. 南四湖表层沉积物中氮形态及吸附释放研究 [学位论文]. 北京: 中国矿业大学, 2007.

[23] 金相灿, 刘鸿亮, 屠清瑛等. 中国湖泊富营养化. 北京: 中国环境科学出版社, 1990, 28(1): 121-133.

[24] 王圣瑞. 湖泊沉积物-水界面过程. 北京: 科学出版社, 2012.

[25] 姜桂华. 铵态氮在土壤中吸附性能探讨. 长安大学学报, 2004, 21(2) : 32-38.

[26] Balci S. Nature of ammonium ion adsorption by sepiolite: analysis of equilibrium data with several isotherms. Water Research, 2004, 38: 1129-1138.

[27] 陈永川, 汤 利, 张德刚等. 滇池水体叶绿素 a 的时空变化及磷对藻类生长的影响. 农业环境科学学报, 2008, 27 (4) : 555-560.

[28] 王雨春, 万国江, 尹澄清等. 红枫湖、百花湖沉积物全氮、可交换态氮和固定铵赋存特征. 湖泊科学, 2002,14 (4) : 301-3091. DOI 10. 18307/2002. 0402.

[29] 李震宇, 朱荫㴮, 王 进. 杭州西湖沉积物的若干物理和化学性状. 湖泊科学, 1998, 10 (1): 79-84. DOI 10. 18307/1998. 0113.

[30] Raaphorst WV, Malschaert JFP. Ammonium adsorption in superficial North Sea sediments. Continental Shelf Research, 1996, 16(11): 1415-1435.

[31] Boatman CD, Murray JW. Modeling exchangeable $\mathrm{NH}_{4}^{+}$adsorption in marine sediments: Process and controls of adsorption. Limnology and Oceanography, 1982, 27: 99-110. 